\title{
The root of the problem: identifying major sources of stress in Brazilian medical students and developing the Medical Student Stress Factor Scale
}

\author{
Rodolfo F. Damiano, ${ }^{1,2}$ (iD Isabella N. de Oliveira, ${ }^{1}$ Oscarina da S. Ezequiel, ${ }^{1}$ (iD Alessandra L. \\ Lucchetti, ${ }^{1}$ Giancarlo Lucchetti ${ }^{1}$ i \\ ${ }^{1}$ Núcleo de Apoio às Práticas Educativas, Faculdade de Medicina, Universidade Federal de Juiz de Fora, Juiz de Fora, MG, Brazil. ${ }^{2}$ Instituto de \\ Psiquiatria, Universidade de São Paulo, São Paulo, SP, Brazil.
}

\begin{abstract}
Objectives: To investigate the most common sources of stress faced by medical students and the degree to which different stressors impact their lives. As a secondary objective, a new instrument, Medical Student Stress Factor Scale (MSSF), was developed based on these stressors.

Methods: The MSSF was applied to 431 medical students. The Depression, Anxiety and Stress Scale was administered to investigate the relationship between these stressors and the students' mental health.

Results: The five greatest stressors were the extensive content, lack of time to study, sleep deprivation, excessive self-pressure for good grades, and lack of leisure time. The MSSF showed good psychometric characteristics, resulting in a 28 -item scale with five subscales. The Relationships and Health subscales were associated with depressive symptoms; Relationships, Health, and Learning Environment/Academic Performance were associated with anxiety symptoms, while Health, and Learning Environment/Academic Performance were associated with stress symptoms.

Conclusions: Our study presents important data about the most important stressors that affect medical students' lives and cause mental health issues. The factors are generally related to academic performance and the learning environment and should be targeted in future interventions.
\end{abstract}

Keywords: Medical students; sources of stress; stress; learning environment; mental health

\section{Introduction}

In recent decades, medical education has been facing serious challenges regarding professionalism and ethical principles, and the high rates of mental health problems are only the tip of the iceberg. Negative aspects of the learning environment, ${ }^{1}$ heavy workloads,${ }^{2-4}$ lack of time, ${ }^{3,4}$ competition among colleagues, ${ }^{2,4}$ financial concerns, ${ }^{2-4}$ health issues, ${ }^{4}$ and peer/faculty relations ${ }^{2}$ are some of most common social and environmental challenges faced by medical students around the world.

The psychological distress that students experience probably mediates these environmental stressors and is key to the mental health crisis. Stress, which can be understood "as a product of two constructs, impinging demands and compromised resources, which conjoin to produce somatic and mental changes that put people at risk for pathology," has already been shown to impact students' well-being and mental health, ${ }^{5}$ resulting in high rates of depression, burnout, ${ }^{6}$ suicidal ideation, and medical school dropouts. ${ }^{7}$

Correspondence: Giancarlo Lucchetti, Núcleo de Apoio às Práticas Educativas, Faculdade de Medicina, Universidade Federal de Juiz de Fora, Av. Eugênio do Nascimento, s/nº Dom Bosco, CEP 36038330, Juiz de Fora, MG, Brazil.

E-mail: g.lucchetti@yahoo.com.br

Submitted Dec 16 2019, accepted Mar 05 2020, Epub Jul 172020.
Brazilian medical education is also embroiled in this heated debate. ${ }^{8} \mathrm{~A}$ recent meta-analysis ${ }^{9}$ found a high prevalence of depressive, anxiety, and stress symptoms, as well as other common mental disorders among Brazilian medical students. Increased stress levels were significantly associated with female sex, first year students, lower family income, dissatisfaction with the course, and using escape/avoidance as a coping strategy. ${ }^{9}$ Furthermore, a cross-cultural comparison ${ }^{10}$ found that Brazilian medical students had more depressive and stress symptoms, more exhaustion, and lower wellness and environmental quality of life than medical students in the USA. Therefore, understanding which factors influence medical students' psychological health is highly necessary, contributing to awareness among medical educators and preventive strategies to minimize negative effects.

Although many studies and instruments around the world have evaluated stress symptoms in clinical, academic, and non-clinical populations, few have been specific to medical education, ${ }^{11,12}$ and even fewer have

How to cite this article: Damiano RF, de Oliveira IN, Ezequiel OS, Lucchetti AL, Lucchetti G. The root of the problem: identifying major sources of stress in Brazilian medical students and developing the Medical Student Stress Factor Scale. Braz J Psychiatry. 2021;43:35-42. http://dx.doi.org/10.1590/1516-4446-2019-0824 
been designed to understand and weigh which stressors have the greatest impact on the mental health and quality of life of medical students. ${ }^{13}$ To our knowledge, few Brazilian studies have assessed the "root of the problem,"10,14-21 and no instruments have been designed to evaluate which specific life situations might be stressful and to what degree they impact the mental health of medical students. The only instrument available in Portuguese for assessing such stressors was developed at the University of Porto, Portugal, ${ }^{13}$ whose conditions differ from those in Brazil. Therefore, an investigation of the main stressors in Brazilian medical students and, consequently, the development of a new instrument to investigate these stressors are necessary.

Thus, to our knowledge, this is the first study designed primarily to qualitatively and systematically investigate the main stressors facing Brazilian medical students during their training. As a secondary objective, a new instrument, the Medical Student Stress Factor Scale (MSSF), was developed based on the most important stressors. The importance of this study is to provide a clear panorama of the stressors impacting medical students and medical education in Brazil, allowing both intra- and international comparisons, as well as suggestions for possible interventions in this rising mental health crisis.

\section{Methods}

This cross-sectional explorative study was conducted between June 2015 and December 2018 in a public medical school in southeastern Brazil. This was a singleinstitution study to obtain preliminary data for a new instrument to evaluate the most common sources of stress in Brazilian medical students.

\section{Instruments}

Sociodemographic data were collected from all participants, including age, ethnicity, sex, year of medical school, family income, and employment.

\section{Depression Anxiety and Stress Scale - 21}

Developed by Lovibond \& Lovibond, ${ }^{22}$ the Depression Anxiety and Stress Scale - 21 (DASS-21) is a 21-item scale for measuring and differentiating stress, depression and anxiety symptoms. Each subscale has seven items measured on a Likert-type scale ranging from "does not apply to me at all" to "applies to me very much." This quick and easy instrument has shown good psychometric properties for analyzing symptoms of the three most prevalent mental health issues. It has also been used in a wide variety of populations, including medical students, ${ }^{23-25}$ and was translated and validated for use in Brazil by Vignola et al. ${ }^{26}$

\section{Medical Student Stress Factor Scale}

To assess the most common stressors experienced by medical students in our context, we carried out an extensive bibliometric review (previously published), ${ }^{1}$ followed by three group discussion encounters with 10-12 medical students of different years, in which they ranked the main stressors they face. The listed items have been discussed by different authors, and some small changes were made to clarify them for the students. An instrument was then designed consisting of 39 distressing life situations (e.g., extensive content, lack of time with friends and family, excessive self-pressure for good grades [Table 1]). For each item students respond to the question "How distressing are each of these situations to you?," with Likert-type options ranging from 1 (not at all) to 7 (extremely distressing). A first draft was tested with 10 students who did not participate in the discussion groups, and they suggested new modifications to some items. After a final review by the authors, the instrument, called the MSSF, was administered to all medical students enrolled in our university. The Portuguese and the proposed English versions of the MSSF

Table 1 Main stressors reported by medical students

\begin{tabular}{ll}
\hline Statement & Mean (SD) \\
\hline Extensive content & $6.01(1.258)$ \\
Lack of time to study & $5.88(1.375)$ \\
Sleep deprivation & $5.74(1.561)$ \\
Excessive self-pressure for good grades & $5.61(1.594)$ \\
Lack of leisure time & $5.60(1.451)$ \\
Exams/evaluations & $5.52(1.550)$ \\
Lack of time with friends and family & $5.37(1.573)$ \\
Extensive homework & $5.33(1.577)$ \\
Faculty pressure & $5.13(1.828)$ \\
Fear of failing any course & $5.10(1.851)$ \\
Fear of failing medical school & $5.06(1.914)$ \\
Competitive environment & $5.05(1.911)$ \\
Lack of time for exercise & $5.02(1.664)$ \\
Grades & $4.98(1.749)$ \\
Difficulty understanding the content & $4.93(1.715)$ \\
Lack of motivation to learn & $4.92(1.651)$ \\
Uncertainties & $4.88(1.777)$ \\
Family pressure & $4.87(2.021)$ \\
Knowing that I will be observed & $4.66(1.976)$ \\
during exams & \\
Ignorance of the criteria used to & $4.64(1.831)$ \\
correct exams & \\
Inability to answer patients' questions & $4.60(1.836)$ \\
Insufficient time to answer all & $4.55(1.889)$ \\
exam questions & \\
Concern about my diet & $4.46(1.731)$ \\
Mental health & $4.27(1.996)$ \\
Physical health & $4.15(1.864)$ \\
Lower grades than peers & $4.06(1.978)$ \\
Poor grades in previous exams & $4.00(2.167)$ \\
from a certain course & \\
Health of family members & $3.97(1.906)$ \\
Multiple-choice questions & $3.93(1.832)$ \\
Financial issues & $3.68(1.904)$ \\
Romantic relationships & $3.02(1.860)$ \\
Peer relationships & $3.01(1.649)$ \\
Interactions with patients & $2.84(1.618)$ \\
Family relationships & $2.59(1.665)$ \\
Complex exam questions & $2.58(1.666)$ \\
Faculty relationships & $2.42(1.412)$ \\
Sexual issues & $2.38(1.680)$ \\
Employment issues & $2.19(1.705)$ \\
(unrelated to medical school) & \\
Substance use &
\end{tabular}

$\mathrm{SD}=$ standard deviation. 
Table 2 Principal component analysis of the Medical Student Stress Factor Scale

\begin{tabular}{|c|c|c|c|c|c|}
\hline & \multicolumn{5}{|c|}{ Component } \\
\hline & 1 & 2 & 3 & 4 & 5 \\
\hline & $\begin{array}{l}\text { Learning Environment/ } \\
\text { Academic Performance }\end{array}$ & Relationships & Health & Lack of time & Learning issues \\
\hline Variance (\%) & 26.98 & 6.86 & 5.31 & 3.95 & 3.80 \\
\hline Grades & 0.770 & & & & \\
\hline Exams/evaluations & 0.763 & & & & \\
\hline Excessive self-pressure for good grades & 0.723 & & & & \\
\hline Extensive content & 0.694 & & & & \\
\hline Fear of failing any course & 0.688 & & & & \\
\hline Faculty pressure & 0.638 & & & & \\
\hline Lack of time to study & 0.637 & & & & \\
\hline Fear of failing medical school & 0.617 & & & & \\
\hline Lower grades than peers & 0.606 & & & & \\
\hline Extensive homework & 0.593 & & & & \\
\hline Family pressure & 0.550 & & & & \\
\hline Competitive environment & 0.504 & & & & \\
\hline Family relationships & & 0.748 & & & \\
\hline Peer relationships & & 0.740 & & & \\
\hline Romantic relationships & & 0.715 & & & \\
\hline Faculty relationships & & 0.587 & & & \\
\hline Sexual issues & & 0.513 & & & \\
\hline Physical health & & & 0.807 & & \\
\hline Mental health & & & 0.725 & & \\
\hline Concern about my diet & & & 0.676 & & \\
\hline Health of family members & & & 0.551 & & \\
\hline Lack of leisure time & & & & 0.789 & \\
\hline Lack of time for exercise & & & & 0.779 & \\
\hline Lack of time with friends and family & & & & 0.671 & \\
\hline Inability to answer patients' questions & & & & & 0.757 \\
\hline Lack of motivation to learn & & & & & 0.589 \\
\hline Difficulty understanding the content & & & & & 0.535 \\
\hline Interaction with patients & & & & & 0.468 \\
\hline Total alpha $=0.911$ & 0.907 & 0.753 & 0.702 & 0.773 & 0.650 \\
\hline
\end{tabular}

are presented in Appendices 1 and 2, available as onlineonly supplementary material.

To investigate the psychometric properties of this newly developed instrument, internal consistency analysis (Cronbach's alpha) and factorial analysis were performed. The final scale consisted of 28 items clustered in five different domains (see Results and Table 2): Learning Environment/Academic Performance; Relationships; Health; Lack of time; and Learning issues.

\section{Procedures}

After institutional review board approval, the investigators visited all first- to sixth-year medical students after class between September and October 2015. To obtain informed consent and distribute all three questionnaires, a brief explanation of study's objectives, risks, and benefits was given to students. Those who did not agree to participate or did not sign the consent form were excluded from the study. It took approximately 20 minutes to fill out all the questionnaires. No compensation, financial or otherwise, was provided to the participants.

\section{Statistical analysis}

Statistical analyses were carried out in SPSS version 21. First, a descriptive analysis was carried out using frequency, percentage, mean, and standard deviation (SD) to determine the sample's sociodemographic characteristics, most important stressors, and levels of depression, anxiety, and stress symptoms.

To assess the factor structure of the MSSF, a principal component analysis (PCA) was performed using Varimax rotation with Kaiser normalization. Eigenvalues greater than 1.0 and scree plots were used to evaluate the component factors, and factor loadings $\geqslant 0.40$ were considered satisfactory. Internal consistencies for the entire scale and for each factor were computed using Cronbach's alpha coefficients.

Weighted descriptive statistics were calculated for the most important stress factors for all participants, for first- through fourth-year students (pre-clinical and clinical), and for fifth- and sixth-year students (clinical clerkship) using the mean and SD of each item. Finally, using linear regression models, an inferential analysis was performed to determine which stress factors were associated with depression, anxiety, and stress symptoms. These models were performed for both the individual items and dimensions found in the PCA. Goodness-of-fit measures, $R^{2}$, and adjusted $R^{2}$ were evaluated. Furthermore, a Pearson correlation coefficient analysis was performed between DASS-21 subscores and sex, year of medical school, and family income. In all analyses, a p-value of 0.05 and a $95 \%$ confidence interval were used. 


\section{Ethics statement}

Institutional review board approval was obtained from the Universidade Federal de Juiz de Fora in 2015, and all included students provided written informed consent.

\section{Results}

Of 767 total medical students, 431 answered all the questionnaire items and were included in the study (response rate $=56.2 \%$ ). Table 3 describes the main sociodemographic aspects of our sample. There was a predominance of white $(67.5 \%)$ unemployed $(98.4 \%)$ women $(55.2 \%)$ whose family income was more than five times the Brazilian minimum monthly wage (51\%) and whose mean age was 21.72 years old. The highest percentage of participants were in their first year $(23.4 \%)$, and the lowest percentage were in their sixth year $(8 \%)$.

Concerning descriptive statistics, the highest DASS-21 scores were in the stress domain (mean $[\mathrm{M}]=8.43, \mathrm{SD}=$ $5.04)$, followed by depression domain ( $M=4.89, S D=$ 4.35) and the anxiety domain $(M=3.98, S D=4.12)$. Table S1, available as online-only supplementary material, shows a correlation between DASS-21 subscores with sex, family income, and year of medical school. All three DASS-21 subitems correlated significantly ( $p<0.01$ ) with year of medical school (anxiety: $r=$ -0.256 ; depression: $r=-0.157$; stress: $r=-0.275)$. Female sex was positively correlated with anxiety $(r=0.200$; $p<0.01)$ and stress $(r=0.223 ; p<0.01)$, and family

\begin{tabular}{|c|c|}
\hline Variable & \\
\hline \multicolumn{2}{|l|}{ Year of medical school } \\
\hline 1st & $101(23.4)$ \\
\hline 2nd & $72(16.7)$ \\
\hline 3rd & $75(17.4)$ \\
\hline 4th & 86 (19.9) \\
\hline 5th & $63(14.6)$ \\
\hline 6 th & $34(8.0)$ \\
\hline \multicolumn{2}{|l|}{ Sex } \\
\hline Male & $193(44.8)$ \\
\hline Female & $238(55.2)$ \\
\hline \multicolumn{2}{|l|}{ Ethnicity } \\
\hline White & $291(67.5)$ \\
\hline Mixed & $118(27.4)$ \\
\hline Black & $18(4.2)$ \\
\hline Other & $4(0.9)$ \\
\hline \multicolumn{2}{|l|}{ Employed } \\
\hline Yes & $7(1.6)$ \\
\hline No & $424(98.4)$ \\
\hline \multicolumn{2}{|l|}{ Family income } \\
\hline Up to 5 times the national min. salary & $211(49.0)$ \\
\hline 6 or more times & $220(51.0)$ \\
\hline Age, mean (SD) & $21.72(2.95)$ \\
\hline
\end{tabular}

income was negatively correlated with depression $(r=$ $-0.107 ; p<0.05)$.

Regarding the main stressors, Table 1 summarizes the mean and SD of each life situation reported by students as distressing. The top five were: extensive content $(M=6.01, S D=1.258)$, lack of time to study $(M=5.88$, $S D=1.375)$, sleep deprivation $(M=5.74, S D=1.561)$, excessive self-pressure for good grades $(M=5.61, S D=$ $1.594)$, and lack of leisure time $(M=5.60, S D=1.451)$. The lowest five were: complex exam questions $(M=2.58$, $S D=1.666)$, faculty relationships $(M=2.42, S D=1.412)$, sexual issues $(M=2.38, S D=1.680)$, employment issues $(M=2.19, S D=1.705)$, and substance use $(M=1.70$, $\mathrm{SD}=1.420)$.

A separate analysis including pre-clerkship students (1st-4th year) and clerkship students (5th-6th year) is shown in Tables S2 and S3, available as online-only supplementary material. Three of the main five stressful situations were identical for both groups: extensive content, lack of time to study, and sleep deprivation. However, for the other two stressors, the junior students reported excessive self-pressure for good grades and exams/evaluations, while senior students reported lack of leisure time and lack of time with family and friends. A PCA was performed and is presented in Table 2. The Kaiser-Meyer value of 0.903 and Barlett's index of 7,126.7 ( $p<0.001$ ) suggested that this data set was appropriate for the PCA procedure. The Cronbach's alpha for the entire scale was 0.911, showing good internal consistency. The PCA procedure yielded five different domains: 1) Learning Environment/Academic Performance ( $\alpha=0.907)$; 2) Relationships ( $\alpha=0.753)$; 3) Health ( $\alpha=0.702)$; 4) Lack of time ( $\alpha=0.773)$; and 5) Learning issues ( $\alpha=0.650$ ); all five domains accounted for $46.9 \%$ of the variance, with each domain accounting for $26.98 \%, 6.86 \%, 5.31 \%, 3.95 \%$, and $3.80 \%$, respectively.

Linear regression was also performed between the DASS-21 subscales and each MSSF domain (Table 4) and item (Table 5). For depression, two domains (Relationships $[\beta=0.166, p=0.001]$ and Health $[\beta=0.139$, $p=0.012]$ ) and four items (mental health $[\beta=0.167$, $p \leqslant 0.00]$, peer relationships $[\beta=0.173, p \leqslant 0.001]$, lack of motivation to learn [ $\beta=0.131, p=0.007]$, and lack of time to study $[\beta=0.113, p=0.020]$ ) appeared to be significant. For anxiety, three domains (Relationships [ $\beta=0.106, p=0.027]$, Health $[\beta=0.124, p=0.019]$, and Learning Environment/Academic Performance $[\beta=$ $0.265, p \leqslant 0.001]$ ) and four items (mental health $[\beta=$ $0.198, p \leqslant 0.001]$, lower grades than peers $[\beta=0.0150$, $p=0.0003]$, family pressure $[\beta=0.0149, p=0.001]$, and exams/evaluations $[\beta=0.143, p=0.004]$ ) were significant. And finally, for stress, we found two domains (Learning Environment/Academic Performance $[\beta=$ 0.316, $p \leqslant 0.001]$ and Health $[\beta=0.155, p=0.003])$ and five items (mental health $[\beta=0.2-8, p \leqslant 0.001]$, difficulty understanding the content $[\beta=0.174, p \leqslant$ $0.001]$, lower grades than peers $[\beta=0.136, p=0.005]$, lack of time to study $[\beta=0.120, p=0.017]$, and family relationships $[\beta=0.110, p=0.012]$ ) to be statistically significant. 
Table 4 Linear regression between Medical Student Stress Factor Scale dimensions and Depression, Anxiety and Stress Scale-21 subscales

\begin{tabular}{|c|c|c|}
\hline Dimension/subscale & Beta & $\mathrm{p}$-value \\
\hline \multicolumn{3}{|l|}{ Depression* } \\
\hline $\begin{array}{l}\text { Learning Environment/ } \\
\text { Academic Performance }\end{array}$ & 0.086 & 0.167 \\
\hline Relationships & 0.166 & 0.001 \\
\hline Health & 0.139 & 0.012 \\
\hline Lack of Time & -0.034 & 0.529 \\
\hline Learning Issues & 0.085 & 0.135 \\
\hline \multicolumn{3}{|l|}{ Anxiety $^{\dagger}$} \\
\hline $\begin{array}{l}\text { Learning Environment/ } \\
\text { Academic Performance }\end{array}$ & 0.265 & $<0.001$ \\
\hline Relationships & 0.106 & 0.027 \\
\hline Health & 0.124 & 0.019 \\
\hline Lack of Time & 0.002 & 0.974 \\
\hline Learning Issues & 0.055 & 0.307 \\
\hline \multicolumn{3}{|l|}{ Stress } \\
\hline $\begin{array}{l}\text { Learning Environment/ } \\
\text { Academic Performance }\end{array}$ & 0.316 & $<0.001$ \\
\hline Relationships & 0.082 & 0.078 \\
\hline Health & 0.155 & 0.003 \\
\hline Lack of Time & 0.004 & 0.930 \\
\hline Learning Issues & 0.041 & 0.442 \\
\hline
\end{tabular}

Bold type denotes statistical significance.

$* R=0.332, R^{2}=0.110$, adjusted $R^{2}=0.100$

$\mathrm{T}=0.426, \mathrm{R}^{2}=0.182$, adjusted $\mathrm{R}^{2}=0.172$.

${ }^{\ddagger} R=0.475, R^{2}=0.225$, adjusted $R^{2}=0.216$.

Table 5 Linear regression between individual items of the Medical Student Stress Factor Scale and the Depression, Anxiety and Stress Scale subscales

\begin{tabular}{lcc}
\hline Dimension/subscale & Beta & p-value \\
\hline Depression* & & \\
$\quad$ Mental health & 0.167 & $<\mathbf{0 . 0 0 1}$ \\
Peer relationships & 0.173 & $<\mathbf{0 . 0 0 1}$ \\
Lack of motivation to learn & 0.131 & $\mathbf{0 . 0 0 7}$ \\
Lack of time to study & 0.113 & $\mathbf{0 . 0 2 0}$ \\
& & \\
Anxiety & & \\
Mental health & 0.198 & $<\mathbf{0 . 0 0 1}$ \\
Lower grades than peers & 0.150 & $\mathbf{0 . 0 0 3}$ \\
Family pressure & 0.149 & $\mathbf{0 . 0 0 1}$ \\
Exams/evaluations & 0.143 & $\mathbf{0 . 0 0 4}$ \\
& & \\
Stress & & \\
$\quad$ Difficulty understanding the content & 0.174 & $<\mathbf{0 . 0 0 1}$ \\
Mental health & 0.208 & $<\mathbf{0 . 0 0 1}$ \\
Lower grades than peers & 0.136 & $\mathbf{0 . 0 0 5}$ \\
$\quad$ Family relationships & 0.110 & $\mathbf{0 . 0 1 2}$ \\
Lack of time to study & 0.120 & $\mathbf{0 . 0 1 7}$ \\
\hline
\end{tabular}

Data presented as beta and $\mathrm{p}$-value.

Bold type denotes statistical significance.

${ }^{*} R=0.389, R^{2}=0.152$, adjusted $R^{2}=0.144$

$R=0.443, R^{2}=0.196$, adjusted $R^{2}=0.188$

$\mathrm{R}=0.510, \mathrm{R}^{2}=0.260$, adjusted $R^{2}=0.251$.

\section{Discussion}

Our results showed that extensive content, lack of time to study, sleep deprivation, excessive self-pressure for good grades, and lack of leisure time were the most stressful situations reported by medical students and that these stressors impact their well-being. This study also produced the MSSF, a novel instrument that could help educators alleviate these stressors.

The MSSF had good psychometric properties, which resulted in five subscales, all of which had adequate internal consistency. In terms of convergent validity, some negative statements and subscales correlated with all three DASS-21 subscales (i.e., depression, anxiety, and stress). Thus, the MSSF shows promise as a systematic measure of the qualitative stressors that medical students encounter during their training. Other instruments for identifying sources of stress among medical students have been developed in South Korea (22 items/7 subscales) ${ }^{2}$ and Portugal (22 items $/ 5$ subscales). ${ }^{13}$ It is interesting to note that certain MSSFS subscales, such as Learning Environment/Academic Performance, Health, and Relationships, were also important in these other international instruments, which indicates that some sources of stress are important all over the world. More studies are needed to determine the MSSF's validity in different contexts and cultures, which will demonstrate whether these stressors have the same impact on medical students in other countries.

The MSSF has some similarities and some differences with the only other instrument available in Portuguese ${ }^{13}$ to assess medical student stressors, the Inventário de Fontes de Estresse Acadêmico no Curso de Medicina (IFSAM) (the Inventory of Sources of Stress During Medical Education). First, the IFSAM was developed in Portugal for medical students who are different from Brazilian students in many repsects. Second, the IFSAM includes some questions that can be answered only during specific phases of the program, such as "uncertanties concerning the clerkship" or "anatomy course requirements." Third, although both scales involve five factors, these factors have some peculiarities. For instance, the IFSAM's Course Requirements factor is similar to the MSSF's Learning Environment/Academic Performance subscale, while the IFSAM's Lifestyle factor could be compared to the MSSF's Lack of Time subscale. However, the other three IFSAM factors (i.e., Human Requirements, Competition, and Adaptation) are mixed subscales that could be included in several MSSF dimensions. In general, the MSSF includes more social issues as causes of stress, such as family and romantic relationships. Likewise, the learning environment is covered more extensively in the MSSF than the IFSAM. Recent studies have found that the learning environment is an important and highly prevalent source of stress among Brazilian students. ${ }^{10}$

As the most common sources of stress, Brazilian medical students reported situations related to learning environment, academic performance, and lack of time, such as extensive content, lack of time to study, sleep deprivation, excessive self-pressure for good grades, lack of leisure time, exams and assessments, and lack of time with friends and family. These results are similar to a small Brazilian pilot study, ${ }^{18}$ which found that unfair professors, extensive content, exams, and lack of leisure time were the most important stressors. It is noteworthy that exams were also among the most important stressors for medical students in Pakistan, ${ }^{27}$ 
Canadia, ${ }^{28}$ Saudi Arabia, ${ }^{29}$ the Netherlands. ${ }^{30}$ This finding reflects the need to rethink current medical curricula to develop less punitive and more practical, longitudinal, and taxonomical assessments.

When analyzing the most common sources of stress during the pre-clinical, clinical, and clinical clerkship years separately, we found interesting results. Students from the first through fourth years of medical school tended to report more academic issues, such as excessive selfpressure for good grades and exams/evaluations, while students from later years reported a lack of time, such as the lack of leisure time and lack of time with friends and family. However, both junior and senior students reported the extensive content, lack of time to study, and sleep deprivation as stressors. These findings are not surprising, since junior students have an extensive workload (such as exams and basic science content), while senior students tend to have greater responsibilities, including inpatient and outpatient contact, which results in less time for leisure activities. ${ }^{31,32}$

Comparing our findings with those of similar studies, Brazilian students tended to be more similar to Dutch students ${ }^{30}$ (i.e., exams, extensive content, self-expectations, lack of time) and Pakistani students ${ }^{27}$ (i.e., frequency of examinations, academic curriculum, sleeping difficulties) and less similar to Malaysian students ${ }^{33}$ (i.e., concern about the future, financial difficulties, difficulties studying, hearing bad news) and Canadian students $^{28}$ (i.e., studying for examinations, finances, relationships). In a narrative review, Dyrbye ${ }^{34}$ listed the most stressful events in American medical training: adjusting to the medical school environment, ethical conflicts, exposure to death and human suffering, student abuse, personal life events, and educational debt.

These similarities and differences are probably related to the academic environment and to curricular and cultural/social factors. For instance, although financial issues seem to be an important problem in Canada due to the high tuition costs, they are not an important issue in Brazil, since public universities do not charge tuition fees. All these findings highlight the importance that students give to their lack of time and the academic climate, such as the large number of exams, extensive content, pressure for good grades, and unfair professors. Targeting the formal curriculum might be a reasonable strategy to alleviate most of these stressors, except for unfair professors, which warrants deeper analysis regarding the hidden curriculum.

Our DASS-21 results for common mental health issues, such as depressive, anxious, and stress symptoms, indicated higher levels of depression, anxiety, and stress than in students from a public medical school in United States, ${ }^{10}$ but lower levels than in students from a private institution in Pakistan, ${ }^{35}$ and much lower levels than in Syrian medical students during wartime. ${ }^{36}$ Furthermore, medical students from early phases of the program had more mental health symptoms than final year students. These findings are consistent with the available literature ${ }^{20,24}$ and have been exhaustively scrutinized in a recent systematic review. ${ }^{9}$
Concerning the relationship between stress symptoms (DASS-Stress) and sources of stress reported by medical students, we found that difficulty understanding the content, mental health issues, lower grades than peers, family relationships, and lack of time to study correlated significantly with this construct. Moreover, the Learning Environment/Academic Performance and Health subscales correlated significantly with DASS-Stress scores. These results were similar to those of a Saudi Arabian study $^{29,37}$ (i.e., academic and health stressors, great exertion studying, difficulty understanding the information in textbooks, being motivated by the family to study), but slightly different than those from Malaysia ${ }^{33}$ (i.e., concern about the future, interpersonal conflicts, and roommate conflicts). A qualitative study regarding perceived stress and medical training in the United Kingdom ${ }^{38}$ also confirmed our hypothesis that employment and academic issues are the most important sources of stress among undergraduate medical students.

On the other hand, the most common sources of stress related to depressive symptoms were relationships, health, mental health, peer relationships, lack of motivation to learn, and lack of time to study. This is in line with a previous South Korean study, ${ }^{2}$ which found that low commitment, teacher-student relationships, a non-supportive climate, and workload were associated with depression. It seems that stress predictors are more related to academic and family factors, while depressive factors are more related to relationships, health, and motivation.

Medical schools should not only be aware of these numerous challenges, but should design interventions to create a better environment for their students, including the formal, informal, and hidden curricula. Regarding the formal curriculum, a recent systematic review ${ }^{39}$ investigated the association of a number of learning environment interventions and their impact on the mental health and well-being of students. Despite the review's low quality of evidence due to the lack of good controlled studies, it found a variety of different interventions that might help medical educators around the world alleviate their students' stress and enhance their well-being. In general, a pass/fail grading system, ${ }^{40}$ mental health programs, ${ }^{41}$ and training in mindfulness ${ }^{42}$ enhanced the students' mental health. Several other curriculum and learning environment interventions also appeared to alleviate stress. ${ }^{43,44}$ More high-quality intervention studies must be conducted to maximize student well-being, mental health, and academic performance.

Furthermore, negative aspects of the learning environment ${ }^{1,45}$ such as unprofessional behaviors, harassment and discrimination, hazing, mistreatment, and an apparent lenience toward unethical behavior might play an important role on the stressors pointed out by students. On the other hand, Shochet et al. ${ }^{46}$ found that inspiring role models, working in a highly functional team, and a perceived contribution to patient care are the three most important experiences that impact medical students' perception of their learning environment. Educators should be aware of the hidden curriculum and the "unspoken truth," which could separate what students actually think 
and what they verbalize. Thus, they can take better aim at the root of the problem, making self-analysis a continuous process and becoming better role models. ${ }^{47}$

This study has several limitations. First, it was a crosssectional study, which means that we cannot determine causal relationships between the stressors and mental health problems. Second, being a single-institution study, it lacks a sufficiently large sample to make it more representative of all medical students. Third, the students might have responded with more socially desirable answers, rather than reporting the real weight of the stressors in their daily lives. Finally, the majority of our sample was students without a clinical clerkship, which might have undervalued other important stressors among older students. One reason for the composition of the sample is that students with clinical clerkships have less time, as well as the fact that many clerkships take place in different cities.

In conclusion, we found many important stressors that might lead to mental health issues, poor grades, and possibly to unprofessional behavior. The MSSF instrument showed good psychometric proprieties and can be used by educators around the world to compare and intervene in the roots of mental health issues among medical students.

\section{Acknowledgements}

The study received funding from Conselho Nacional de Desenvolvimento Científico e Tecnológico (CNPq) from August 2015 to July 2016. GL received a level 2 research productivity scholarship (medicine) from CNPq.

\section{Disclosure}

The authors report no conflicts of interest.

\section{References}

1 Damiano RF, da Cruz AO, de Oliveira JG, DiLalla LF, Tackett S, Ezequiel OS, et al. Mapping the scientific research on the negative aspects of the medical school learning environment. Rev Assoc Med Bras. 2018;64:1050-7.

2 Shim EJ, Jeon HJ, Kim H, Lee KM, Jung D, Noh HL, et al. Measuring stress in medical education: validation of the Korean version of the higher education stress inventory with medical students. BMC Med Educ. 2016;16:302.

3 Chang E, Eddins-Folensbee F, Coverdale J. Survey of the prevalence of burnout, stress, depression, and the use of supports by medical students at one school. Acad Psychiatry. 2012;36:177-82.

4 Hill MR, Goicochea S, Merlo LJ. In their own words: stressors facing medical students in the millennial generation. Med Educ Online. 2018;23:1530558.

5 Yusoff MS, Abdul Rahim AF, Baba AA, Ismail SB, Mat Pa MN Esa AR. The impact of medical education on psychological health of students: a cohort study. Psychol Health Med. 2013;18:420-30.

6 Dyrbye L, Shanafelt T. A narrative review on burnout experienced by medical students and residents. Med Educ. 2016;50:132-49.

7 O'Neill LD, Wallstedt B, Eika B, Hartvigsen J. Factors associated with dropout in medical education: a literature review. Med Educ. 2011;45:440-54

8 Kassab P, Lourenço LG, Ilias EJ, Malheiros CA. A tragédia do ensino médico no Brasil. Rev Assoc Med Bras. 2013;59:305-6.

9 Pacheco JP, Giacomin HT, Tam WW, Ribeiro TB, Arab C, Bezerra IM, et al. Mental health problems among medical students in Brazil: a systematic review and meta-analysis. Braz J Psychiatry. 2017;39: 369-78.

10 Lucchetti G, Damiano RF, DiLalla LF, Lucchetti AL, Moutinho IL, da Silva Ezequiel $\mathrm{O}$, et al. Cross-cultural differences in mental health, quality of life, empathy, and burnout between US and Brazilian medical students. Acad Psychiatry. 2018;42:62-7.

11 Johnson JC, Degenhardt BF, Smith CK, Wolf TM, Peterson DF. Tool for predicting medical student burnout from sustained stress levels: factor analysis of the medical education hassles scale-R. J Am Osteopath Assoc. 2018;118:170-80.

$12 \mathrm{Kim}$ MJ, Park KH, Yoo HH, Park leB, Yim J. Development and validation of the medical student stress scale in Korea. Korean $\mathrm{J}$ Med Educ. 2014;26:197-208.

13 Loureiro EMF, McIntyre TM, Mota-Cardoso R, Ferreira MA. Inventário de fontes de estresse acadêmico no curso de medicina (IFSAM). Rev Bras Educ Med. 2009;33:191-7.

14 Bassols AMS, Carneiro BB, Guimarães GC, Okabayashi LMS, Carvalho FG, da Silva $A B$, et al. Stress and coping in a sample of medical students in Brazil. Arch Clin Psychiatry (São Paulo). 2015;42:1-5.

15 Bassols AM, Sordi AO, Eizirik CL, Seeger GM, Rodrigues GS, Reche M. Prevalence of stress in a sample of medical students of Universidade Federal do Rio Grande do Sul. Clin Biomed Res. 2008;28:153-7.

16 Aguiar SM, Vieira APGF, Vieira KMF, Aguiar SM, Nóbrega JO. Prevalência de sintomas de estresse nos estudantes de medicina. J Bras Psiquiatr. 2009;58:34-8.

17 Guimarães KB. Estresse e a formação médica: implicações na saúde mental dos estudantes [dissertation]. Faculdade de Ciências e Letras, Universidade Estadual Paulista; 2005.

18 Furtado EdS, Falcone EMdO, Clark C. Avaliação do estresse e das habilidades sociais na experiência acadêmica de estudantes de medicina de uma universidade do Rio de Janeiro. Inter Psicol. 2003;7:43-51.

19 Matos e Souza FG, Menezes MdGC. Stress in medical students at the Federal University in Ceará, Brazil. Rev Bras Educ Med. 2005;29:91-6.

20 Moutinho ILD, Maddalena NdCP, Roland RK, Lucchetti ALG, Tibiriçá SHC, Ezequiel OS, et al. Depression, stress and anxiety in medical students: a cross-sectional comparison between students from different semesters. Rev Assoc Med Bras. 2017;63:21-8.

21 Santos FS, Maia CRC, Faedo FC, Gomes GPC, Nunes ME, Oliveira MVMd. Estresse em estudantes de cursos preparatórios e de graduação em medicina. Rev Bras Educ Med. 2017;41:194-200.

22 Lovibond PF, Lovibond SH. The structure of negative emotional states: comparison of the depression anxiety stress scales (DASS) with the Beck depression and anxiety inventories. Behav Res Ther. 1995;33:335-43.

23 Damiano RF, Furtado AO, da Silva BN, Ezequiel OD, Lucchetti AL, DiLalla LF, et al. Measuring students' perceptions of the medical school learning environment: translation, transcultural adaptation, and validation of 2 instruments to the Brazilian Portuguese language. J Med Educ Curric Dev. 2020 Jan 27;7:2382120520902186. doi: 10.1177/2382120520902186. eCollection 2020 Jan-Dec.

24 Moutinho IL, Lucchetti AL, Ezequiel ODS, Lucchetti G. Mental health and quality of life of Brazilian medical students: Incidence, prevalence, and associated factors within two years of follow-up. Psychiatry Res. 2019;274:306-12.

25 Bechara Secchin LS, da Silva Ezequiel O, Vitorino LM, Lucchetti AL, Lucchetti G. Implementation of a longitudinal mentorship program for quality of life, mental health, and motivation of Brazilian medical students. Acad Psychiatry. 2020:44200-4.

26 Vignola RC, Tucci AM. Adaptation and validation of the depression, anxiety and stress scale (DASS) to Brazilian Portuguese. J Affect Disord. 2014;155:104-9.

27 Shah M, Hasan S, Malik S, Sreeramareddy CT. Perceived stress, sources and severity of stress among medical undergraduates in a Pakistani medical school. BMC Med Educ. 2010;10:2.

28 Matheson KM, Barrett T, Landine J, McLuckie A, Soh NL, Walter G. Experiences of psychological distress and sources of stress and support during medical training: a survey of medical students. Acad Psychiatry. 2016;40:63-8.

29 Gazzaz ZJ, Baig M, Al Alhendi BS, Al Suliman MM, Al Alhendi AS, Al-Grad MS, et al. Perceived stress, reasons for and sources of stress among medical students at Rabigh Medical College, 
King Abdulaziz University, Jeddah, Saudi Arabia. BMC Med Educ. 2018;18:29.

30 Yen Yee L, Yusoff MSB. Prevalence and sources of stress among medical students in Universiti Sains Malaysia and Universiteit Maastricht. Educ Med J. 2013;5:e34-41.

31 Kopelman L. Cynicism among medical students. JAMA. 1983;250: 2006-10.

32 Wolf TM, Balson PM, Faucett JM, Randall HM. A retrospective study of attitude change during medical education. Med Educ. 1989;23: 19-23.

33 Al-Dubai SA, Al-Naggar RA, Alshagga MA, Rampal KG. Stress and coping strategies of students in a medical faculty in Malaysia. Malays J Med Sci. 2011;18:57-64.

34 Dyrbye LN, Thomas MR, Shanafelt TD. Medical student distress: causes, consequences, and proposed solutions. Mayo Clin Proc. 2005;80:1613-22.

35 Azim SR, Baig M. Frequency and perceived causes of depression, anxiety and stress among medical students of a private medical institute in Karachi: a mixed method study. J Pak Med Assoc. 2019;69:840-5.

36 Al Saadi T, Zaher Addeen S, Turk T, Abbas F, Alkhatib M. Psychological distress among medical students in conflicts: a cross-sectional study from Syria. BMC Med Educ. 2017;17:173.

37 Abdel Rahman AG, Al Hashim BN, Al Hiji NK, Al-Abbad Z. Stress among medical Saudi students at college of medicine, King Faisal University. J Prev Med Hyg. 2013;54:195-9.

38 Radcliffe C, Lester $\mathrm{H}$. Perceived stress during undergraduate medical training: a qualitative study. Med Educ. 2003;37:32-8.

39 Wasson LT, Cusmano A, Meli L, Louh I, Falzon L, Hampsey M, et al. Association between learning environment interventions and medical student well-being: a systematic review. JAMA. 2016;316: 2237-52.

40 Reed DA, Shanafelt TD, Satele DW, Power DV, Eacker A, Harper W, et al. Relationship of pass/fail grading and curriculum structure with well-being among preclinical medical students: a multi-institutional study. Acad Med. 2011;86:1367-73.

41 Thompson D, Goebert D, Takeshita J. A program for reducing depressive symptoms and suicidal ideation in medical students. Acad Med. 2010;85:1635-9.

42 Erogul M, Singer G, McIntyre T, Stefanov DG. Abridged mindfulness intervention to support wellness in first-year medical students. Teach Learn Med. 2014;26:350-6.

43 Dorsey JK, Roberts NK, Wold B. Feedback matters: the impact of an intervention by the dean on unprofessional faculty at one medical school. Acad Med. 2014;89:1032-7.

44 Smith SD, Dunham L, Dekhtyar M, Dinh A, Lanken PN, Moynahan $\mathrm{KF}$, et al. Medical student perceptions of the learning environment: learning communities are associated with a more positive learning environment in a multi-institutional medical school study. Acad Med. 2016;91:1263-9.

45 Benbassat $\mathrm{J}$. Undesirable features of the medical learning environment: a narrative review of the literature. Adv Health Sci Educ Theory Pract. 2013;18:527-36.

46 Shochet RB, Colbert-Getz JM, Wright SM. The Johns Hopkins learning environment scale: measuring medical students' perceptions of the processes supporting professional formation. Acad Med. 2015;90:810-8.

47 Joynt GM, Wong WT, Ling L, Lee A. Medical students and professionalism - Do the hidden curriculum and current role models fail our future doctors? Med Teach. 2018;40:395-9. 